\title{
The Relationship Between Ambient Air Pollution and Hospitalizations for Gout in a Humid Subtropical Region of China
}

\author{
Yi-Sheng $\mathrm{He}^{1,2, *}$ \\ Gui-Hong Wang ${ }^{3, *}$ \\ Qian $\mathrm{Wu}^{1,2, *}$ \\ Zheng-Dong $\mathrm{Wu}^{1,2}$ \\ Yue Chen ${ }^{1,2}$ \\ Jin-Hui Tao $\mathbb{D}^{4}$ \\ Xin-Yu Fang ${ }^{1,2}$ \\ Zhiwei $\mathrm{Xu}^{5}$ \\ Hai-Feng Pan ${ }^{1,2}$ \\ 'Department of Epidemiology and \\ Biostatistics, School of Public Health, \\ Anhui Medical University, Hefei, Anhui, \\ People's Republic of China; ${ }^{2}$ Inflammation \\ and Immune Mediated Diseases \\ Laboratory of Anhui Province, Hefei, \\ Anhui, People's Republic of China; \\ ${ }^{3}$ Department of Rheumatology, Anqing \\ Hospital Affiliated to Anhui Medical \\ University, Anqing, Anhui, People's \\ Republic of China; ${ }^{4}$ Department of \\ Rheumatology and Immunology, The First \\ Affiliated Hospital of USTC, Division of \\ Life Sciences and Medicine, University of \\ Science and Technology of China, Hefei, \\ People's Republic of China; ${ }^{5}$ School of \\ Public Health, Faculty of Medicine, \\ University of Queensland, Brisbane, \\ QLD, Australia
}

*These authors contributed equally to this work

Correspondence: Zhiwei Xu; Hai-Feng

Pan

Email xzwI0II@gmail.com;

panhaifeng1982@sina.com
Objective: Gout is a chronic disease caused by the deposition of sodium urate (MSU) crystals. Available data on the association between environmental hazards and gout are scarce. The present study was present to investigate the relationship between short-term exposure to air pollution and hospitalizations for acute gout from 2016 to 2020 in Anqing City, China.

Methods: Daily records of hospital admissions for acute gout in Anqing from 1 January 2016 to 31 December 2020 were retrieved from the tertiary first-class hospitals in Anqing. Air pollutants and meteorological data were obtained from the China Environmental Monitoring Station and China Meteorological Data Service Center respectively. We used a time-series analysis to explore the association between air pollution $\left(\mathrm{NO}_{2}, \mathrm{O}_{3}\right.$, and $\left.\mathrm{CO}\right)$ and hospitalizations for acute gout, and conducted stratified analyses by gender, age and season.

Results: We observed an association between $\mathrm{NO}_{2}$ and hospitalizations for gout (lag 0 , relative risk (RR): $1.022,95 \%$ confidence interval (CI):1.004-1.041). For every $1 \mathrm{mg} / \mathrm{m}^{3}$ increase in CO concentration, hospitalizations for gout increased by $3.9 \%$ (lag 11 days, $\mathrm{RR}=1.039,95 \% \mathrm{CI}$ : 1.004-1.076). Intriguingly, there was a negative association between $\mathrm{O}_{3}$ and hospitalizations for gout (lag0, RR=0.986, 95\% CI: 0.976-0.996). Stratified analyses showed that exposure to high levels of $\mathrm{NO}_{2}$ was considered to be more vulnerable to gout in cold season.

Conclusion: Our study showed that short-term exposure to $\mathrm{NO}_{2}$ and $\mathrm{CO}$ has a significant effect on hospitalizations for acute gout.

Keywords: gout, air pollutants, carbon monoxide, nitrogen dioxide, ozone

\section{Introduction}

Gout is a chronic inflammatory disease characterized by continuously increased uric acid levels and precipitation of sodium urate (MSU) crystals in joints and surrounding tissues. $^{1,2}$ The disease impacts approximately $1 \%$ to $4 \%$ of the population worldwide, and it is more common in men than women. ${ }^{3}$ Gout has become the most common inflammatory disease in adults, ${ }^{3}$ and it not only has an adverse impact on the quality of life of patients, but also brings considerable economic burden to the society. However, the pathogenesis and development of gout have not yet been adequately elucidated. Emerging evidence has suggested that metabolic, genetic, immune and environmental factors may play a role in the pathogenesis of gout.

Air pollution is detrimental to health. Carbon monoxide $(\mathrm{CO})$, nitrogen dioxide $\left(\mathrm{NO}_{2}\right)$ and other air pollutants may be involved in the biological mechanisms that evoke the increase of free radicals in the body, activate the immune system and trigger inflammation., ${ }^{4,5}$ Epidemiological studies have 
shown that air pollutants were associated with increased risks of various diseases such as atopic dermatitis, ${ }^{6,7}$ diabetes mellitus $(\mathrm{DM})^{8,9}$ and multiple sclerosis. ${ }^{10,11}$ Our previous studies have found associations of air pollutants with hospitalizations for systemic lupus erythematosus (SLE) and rheumatoid arthritis (RA). ${ }^{12,13}$ Adami et al found that long-term exposure to air pollutants was associated with the development of osteoporosis and chronic inflammatory arthritis. ${ }^{14,15}$ Ryu et al have also reported that $\mathrm{PM}_{10}$ exposure may increase the risk of acute gout attack. ${ }^{16}$ A large cohort study conducted in Taiwan found that air pollution exposure increased the risk of hospitalizations for gout, ${ }^{17}$ and this health effect of air pollution may be because of oxidative stress and inflammation, but the exact mechanisms need to be further explored. However, to the best of our knowledge, available data on the relationship between air pollutants and gout in humid subtropical regions are still scarce. In this timeseries study, we investigated the association between air pollutants and the hospitalizations for acute gout in Anqing City, and identified the susceptible subpopulations and season.

\section{Materials and Methods \\ Study Area}

This study was conducted in Anqing, Anhui Province, one of the central cities of Yangtze River Delta $\left(29^{\circ} 47^{\circ} \sim 31^{\circ}\right.$ $\left.16^{\prime} \mathrm{N}, 115^{\circ} 45^{\prime} \sim 117^{\circ} 44^{\prime} \mathrm{E}\right)$. The population of Anqing City in 2019 was 4.723 million. It has a subtropical humid climate. $^{18}$

\section{Gout Data}

Daily records of hospital admissions for acute gout in Anqing from 1 January 2016 to 31 December 2020 were retrieved from Anqing Municipal Hospital Affiliated to Anhui Medical University, Anqing First People's Hospital, Anqing Naval Hospital and Anqing Qianshan Municipal Hospital, the four tertiary first-class hospitals in Anqing which the majority of gout patients sought medical help from. Data included variables such as age, gender, admission date, and residential address. Meanwhile, patients whose residential address was not in Anqing or without demographic information (eg, age and gender) were excluded. All gout patients were diagnosed by two rheumatologists according to ACR criteria. The ethics approval was granted by the Ethics Committee of Anhui Medical University.

\section{Air Pollutants and Meteorological Data}

Data on air pollution (24-h for $\mathrm{NO}_{2}, \mathrm{CO}, \mathrm{PM}_{2.5}, \mathrm{PM}_{10}$ and 8-h for $\mathrm{O}_{3}$ ) from 2016 to 2020 were obtained from the China Environmental Monitoring Station. The data were originally gathered from 10 air quality monitoring stations in Anqing City. Daily relative humidity (\%) and mean temperature $\left({ }^{\circ} \mathrm{C}\right)$ data during the study period were provided by China Meteorological Data Service Center (http://data.cma.cn/).

\section{Statistical Analysis}

We obtained the correlation coefficients between air pollutants, meteorological factors and the daily number hospitalization for acute gout through Spearman analysis and scatter plot. Since the daily gout admissions are small probability events, generalized linear model (GLM) with quasi-Poisson distribution was used to explore the relationship between air pollutants and the daily hospitalizations for gout. ${ }^{19}$ In order to avoid multicollinearity, Spearman correlation coefficient less than 0.7 was used for covariate selection. Finally, the model is shown as below:

$$
Y_{t} \text { quasipossion }\left(\mu_{t}\right)
$$

$$
\begin{aligned}
\log \left(\mu_{t 1}\right)_{N_{2}}= & \alpha_{1}+\beta_{1} N_{2 t, l}+n s\left(P_{2.5}, 3\right)+n s\left(S_{2}, 3\right) \\
& +n s(\text { RH, 3 })+n s(\text { Time }, 6 * 5)+\eta_{1} \mathrm{DOW}_{t} \\
& +\gamma_{1} \text { Holiday }_{t} \\
\log \left(\mu_{t 2}\right)_{O_{3}}= & \alpha_{2}+\beta_{2} O_{3 t, l}+n s(M T, 4)+n s(C O, 4) \\
& +n s(\text { RH }, 4)+n s(\text { Time }, 6 * 5)+\eta_{2} \text { DOW }_{t} \\
& +\gamma_{2} \text { Holiday }_{t}
\end{aligned}
$$

$$
\begin{aligned}
\log \left(\mu_{t 3}\right)_{C O}= & \alpha_{3}+\beta_{3} C O_{t, l}+n s\left(O_{3}, 4\right)+n s\left(S_{2}, 4\right) \\
& +n s(\text { Time }, 8 * 5)+\eta_{3} D O_{t}+\gamma_{3} \text { Holiday }_{t}
\end{aligned}
$$

Where the subscript $t$ refers to the day of observation, $Y_{t}$ and $u_{t}$ are the actual and expected gout hospitalizations on day $t$, respectively. In the $\mathrm{NO}_{2}$ model, $\alpha_{1}$ represents the intercept of the model. $\mathrm{NO}_{2} \mathrm{t}, 1$ is the dlnm cross basis matrix of $\mathrm{NO}_{2 \mathrm{t}}$, $l$ refers to the lag day, $\beta_{1}$ is the vector of $\mathrm{NO}_{2 \mathrm{t}}$, ns () means natural cubic spline. A natural cubic spline curve with $6 d f_{S} /$ year was used to control for seasonality and long-term trend. ${ }^{20}$ $D O W$ is the dummy variable of the day of the week; the binary variable Holiday Has used to control for holiday effect. The quasi-Poisson Akaike Information Criterion (Q-AIC) was used to identify the optimal $d f s$ and to select the final model 
Table I Summary Statistics of Admissions for Gout, Meteorological Variables and Air Pollutants in Anqing, China, 2016-2020

\begin{tabular}{|c|c|c|c|c|c|c|c|c|}
\hline \multirow[t]{2}{*}{ Variables } & \multirow[t]{2}{*}{ Number } & \multirow[t]{2}{*}{ Mean (SD) } & & \multicolumn{5}{|c|}{ Centiles } \\
\hline & & & Min & Median & IQR & $\operatorname{Max}$ & $\mathbf{P}_{10}$ & $\mathbf{P}_{90}$ \\
\hline Admissions & 8675 & $4.75(3.59)$ & 0 & 4 & 5 & 21 & 1 & 10 \\
\hline Male & 7873 & $4.31(3.34)$ & 0 & 4 & 4 & 20 & 1 & 9 \\
\hline Age $<65$ & 5468 & $2.99(2.50)$ & 0 & 2 & 3 & 15 & 0 & 7 \\
\hline Warm Season & 5140 & $2.81(3.92)$ & 0 & 0 & 5 & 21 & 0 & 9 \\
\hline Cold Season & 3535 & $1.93(2.87)$ & 0 & 0 & 3 & 16 & 0 & 6 \\
\hline Mean temperature, ${ }^{\circ} \mathrm{C}$ & - & 17.24(8.97) & -5.28 & 17.90 & 15.59 & 34 & 4.60 & 28.80 \\
\hline Relative humidity, \% & - & $78.6 I(12.15)$ & 39 & 79.30 & 17.9 & 99 & 62 & 94 \\
\hline $\mathrm{PM}_{2.5}, \mathrm{ug} / \mathrm{m}^{3}$ & - & $49.91(32.77)$ & 7 & $4 \mid$ & 34 & 272 & 19 & 93 \\
\hline $\mathrm{PM}_{10}, \mathrm{ug} / \mathrm{m}^{3}$ & - & $65.39(39.03)$ & 9 & 56 & 44 & 367 & 26 & 116 \\
\hline $\mathrm{NO}_{2}, \mathrm{ug} / \mathrm{m}^{3}$ & - & $31.58(15.79)$ & 8 & 27 & 20 & 113 & 16 & 54 \\
\hline $\mathrm{CO}, \mathrm{mg} / \mathrm{m}^{3}$ & - & $0.7 I(0.24)$ & 0.1 & 0.7 & 0.3 & 2.0 & 0.4 & 1.0 \\
\hline $\mathrm{SO}_{2}, \mathrm{ug} / \mathrm{m}^{3}$ & - & $12.22(6.08)$ & 4 & 10 & 13 & 72 & 6 & 21 \\
\hline $\mathrm{O}_{3}, \mathrm{ug} / \mathrm{m}^{3}$ & - & $93.40(40.73)$ & 12 & 91 & 58 & 235 & 41 & 147 \\
\hline
\end{tabular}

Abbreviations: $\mathrm{PM}_{2.5}$, particulate matter $\leq 2.5$ microns in aerodynamic diameter; $\mathrm{PM}_{10}$, particulate matter $\leq 10$ microns in aerodynamic diameter; $\mathrm{NO}_{2}$, Nitrogen Dioxide; $\mathrm{CO}$, Carbon monoxide; $\mathrm{SO}_{2}$, Sulfur dioxide; $\mathrm{O}_{3}$, ozone.

parameters. ${ }^{21}$ To identify susceptible populations, further stratified analyses were performed by age $(<65$ years vs $\geq 65$ years) and gender (male vs female). The association between air pollution and hospitalizations for gout during the warm season (April-September) and the cold season (OctoberMarch) was also examined respectively. All statistical analyses and visualization were performed by R software version 3.6.1 (http://www.R-project.org) with "dlnm" and "splines" packages. For all statistical tests, $\mathrm{P}<0.05$ (two-sided) were considered as statistically significant.

\section{Sensitivity Analysis}

To check the robustness of our model, sensitivity analyses were performed by varying the $d f s$ in the ns function of air pollutants $(3-5 d f s)$, meteorological variables $(3-5 d f s)$ and time (6-8 $d f s$ per year).

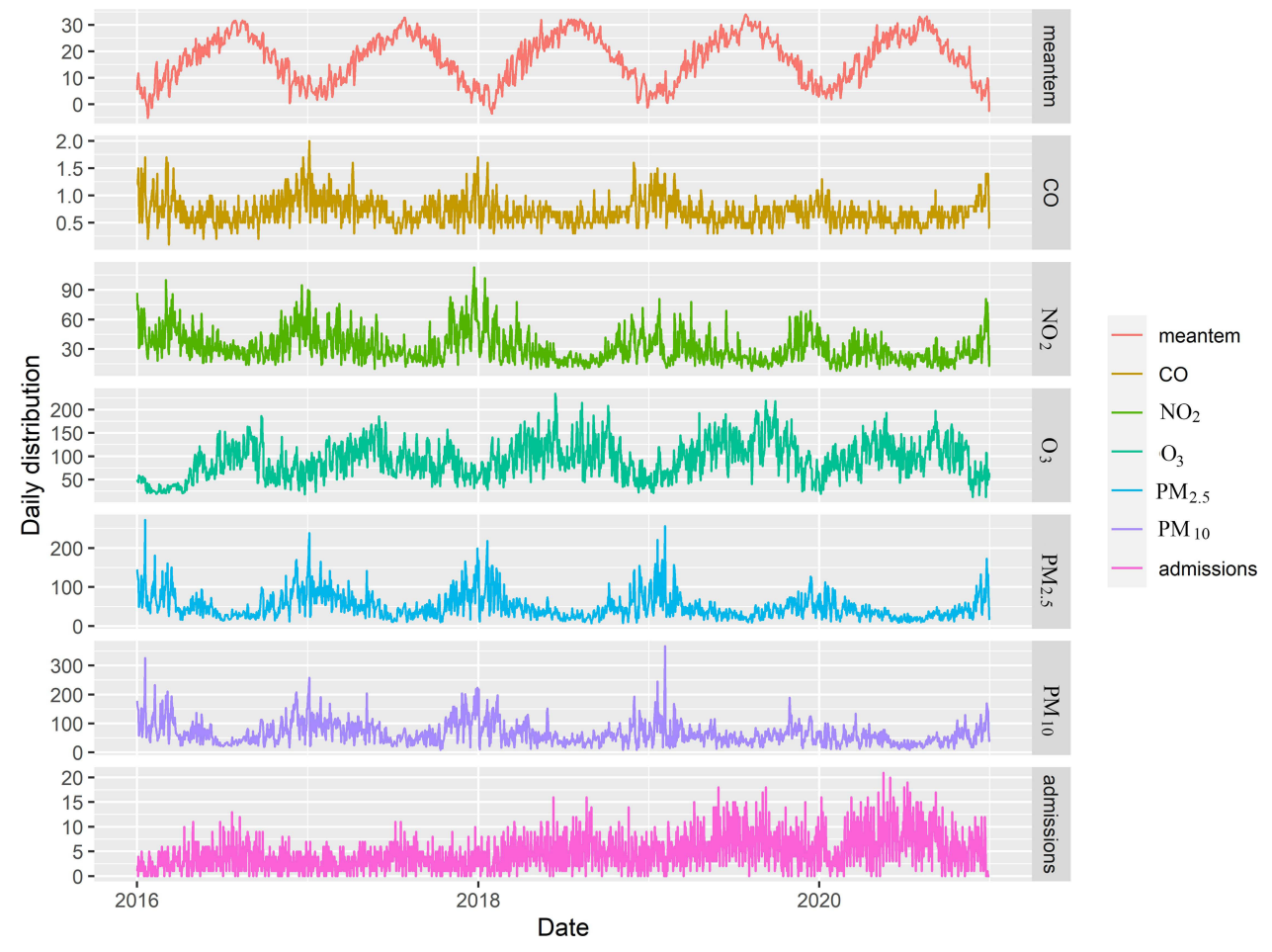

Figure I Time series of gout, $\mathrm{NO}_{2}, \mathrm{O}_{3}$, and $\mathrm{CO}$ in Anqing, China, from 2016 to 2020. 


\section{Results}

\section{Descriptive Analysis}

The characteristics of hospitalized gout cases, meteorological factors and ambient air pollutants in Anqing City are shown in Table 1. A total of 8675 gout admissions were reported in Anqing City from 1 January 2016 to 31 December 2020. Among them, 7873 cases (90.76\%) were male and 3207 cases (36.97\%) were over 65 years old. More people were admitted to hospital for gout during warm season than during cold season (5140 vs 3535 ). The average daily concentrations for $\mathrm{NO}_{2}, \mathrm{CO}$, and $\mathrm{O}_{3}$ (24-h for $\mathrm{NO}_{2}, \mathrm{CO}$ and $8-\mathrm{h}$ for $\left.\mathrm{O}_{3}\right)$ were $31.58 \mu \mathrm{g} / \mathrm{m}^{3}\left(8 \mu \mathrm{g} / \mathrm{m}^{3}\right.$ $\left.113 \mu \mathrm{g} / \mathrm{m}^{3}\right), 0.71 \mathrm{mg} / \mathrm{m}^{3}\left(0.1 \mathrm{mg} / \mathrm{m}^{3}-2.0 \mathrm{mg} / \mathrm{m}^{3}\right)$ and 93.40 $\mu \mathrm{g} / \mathrm{m}^{3} \quad\left(12 \mu \mathrm{g} / \mathrm{m}^{3}-235 \mu \mathrm{g} / \mathrm{m}^{3}\right)$, respectively. During the study period, the number of daily hospitalizations for gout ranged from 0 to 21 . The time-series distributions of air pollutants and the number of people hospitalized for gout in Anqing City from 1 January 2016 to 31 December 2020 are presented in Figure 1. The relative humidity, mean temperature and hospitalizations for gout had distinct seasonal pattern. Spearman rank correlation analysis and scatter plots are described in Figure S1. In order to avoid multicollinearity, only covariates with Spearman correlation coefficient less than 0.7 were included in the regression models.

\section{Overall Effects}

Figure 2 shows the exposure-response relationships between daily hospitalizations for gout and air pollutants $\left(\mathrm{NO}_{2}, \mathrm{CO}\right.$, and $\left.\mathrm{O}_{3}\right)$ in different lag days, indicating that exposure to high concentrations of $\mathrm{NO}_{2}$ and $\mathrm{CO}$ (reference concentrations of $40 \mathrm{ug} / \mathrm{m}^{3}$ and $0.7 \mathrm{mg} / \mathrm{m}^{3}$, respectively) were associated with an increased risk of hospitalizations for gout. High concentration of $\mathrm{O}_{3}$ (reference concentration is $91 \mathrm{ug} / \mathrm{m}^{3}$ ) was also associated with the risk of hospitalizations for gout. The concentration-response relationships of $\mathrm{NO}_{2}, \mathrm{CO}$ and $\mathrm{O}_{3}$ with daily hospitalizations for acute gout flares are presented in Figure S2.

\section{$\mathrm{NO}_{2}$ Effects}

Figure 3 shows that there was a strong correlation between $\mathrm{NO}_{2}$ and hospitalizations for gout (lag0, RR:1.022, 95\% CI:1.004-1.041; and lag1, RR: 1.013 , 95\% CI: $1.003-$ 1.022 , per $10 \mu \mathrm{g} / \mathrm{m}^{3}$ increase in $\mathrm{NO}_{2}$ concentration). The detailed single-day and cumulative effects of $\mathrm{NO}_{2}$ are presented in Table S1.
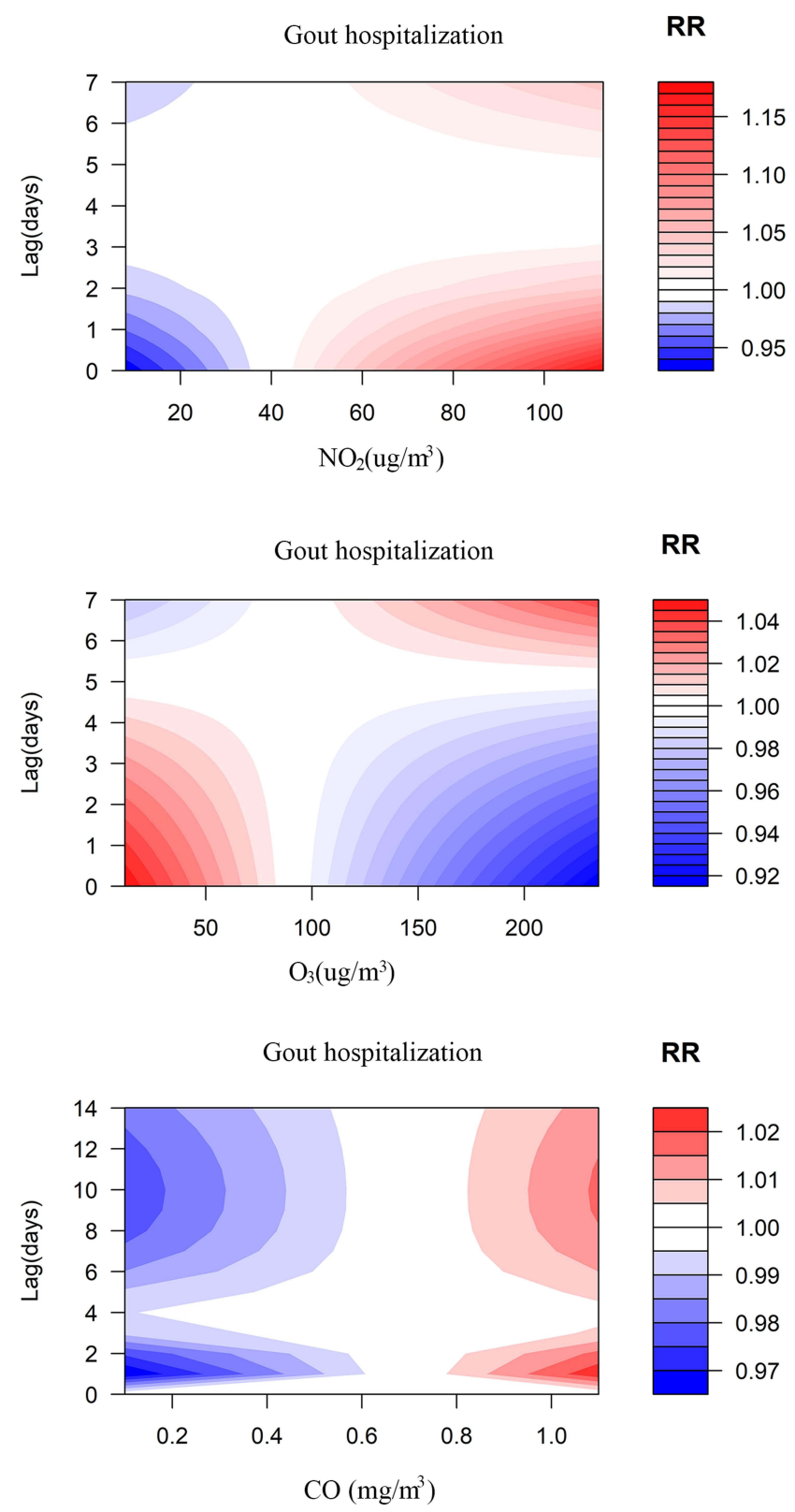

Figure 2 Contour plots for relative risk (RR) of gout hospital admissions along $\mathrm{NO}_{2}, \mathrm{O}_{3}$ and $\mathrm{CO}$ at lag periods in Anqing, China, 2016-2020.

Stratified analyses by gender show that the effect of $\mathrm{NO}_{2}$ exposure on male patients was statistically significant (RR:1.022, 95\% CI: 1.003-1.042, lag 0). When stratified by age, we observed significant association between exposure to $\mathrm{NO}_{2}$ and an increased risk of gout hospitalizations in people $<65$ and people $\geq 65$ years. In addition, exposure to $\mathrm{NO}_{2}$ in cold seasons was associated with an increased risk of hospitalizations for gout (RR: 1.024, 95\% CI: 1.003-1.044, lag 0) (Figure 4 and Table S2). 
A lag-specific effects of ambient pollution

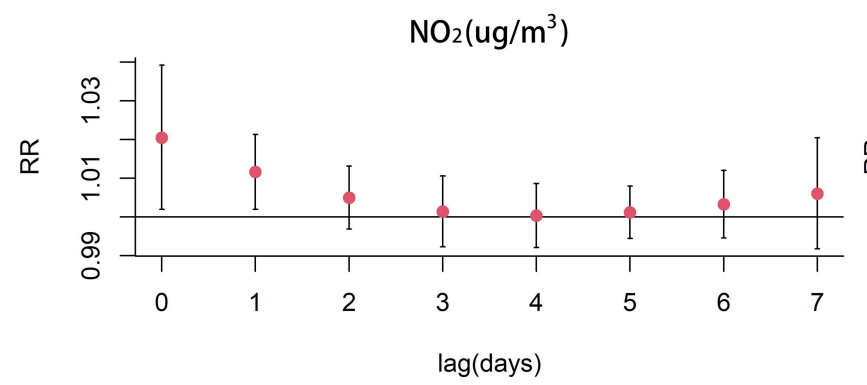

$\mathrm{O}_{3}\left(\mathrm{ug} / \mathrm{m}^{3}\right)$

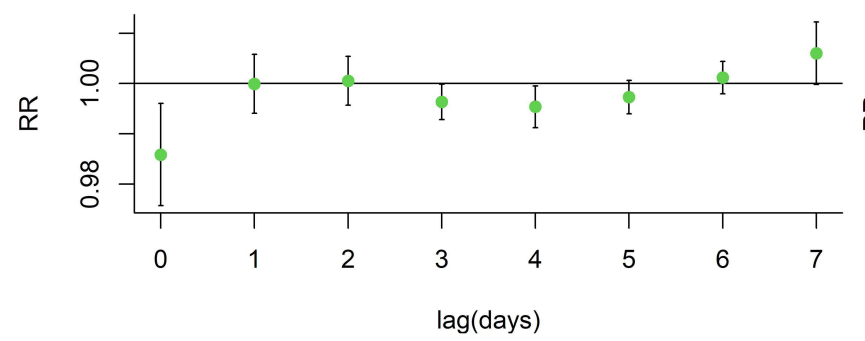

$\mathrm{CO}\left(\mathrm{mg} / \mathrm{m}^{3}\right)$

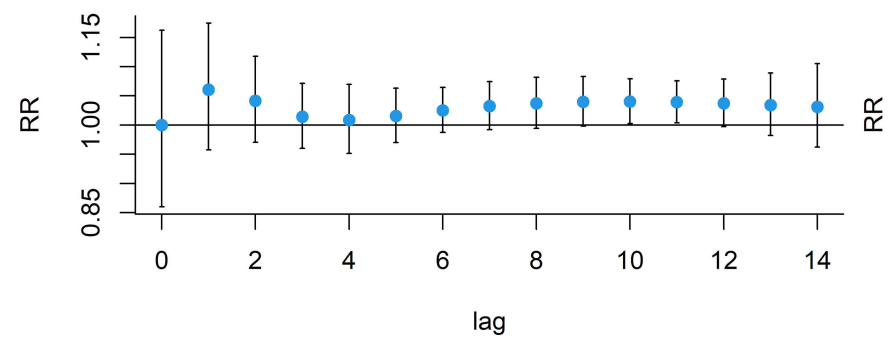

B cumulative effects of ambient pollution

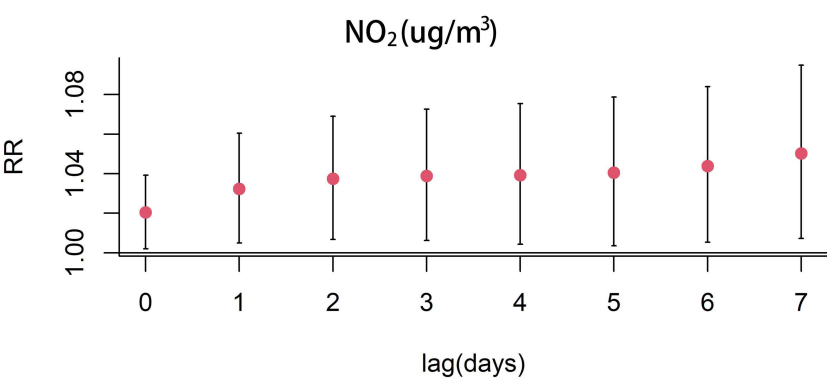

$\mathrm{O}_{3}\left(\mathrm{ug} / \mathrm{m}^{3}\right)$

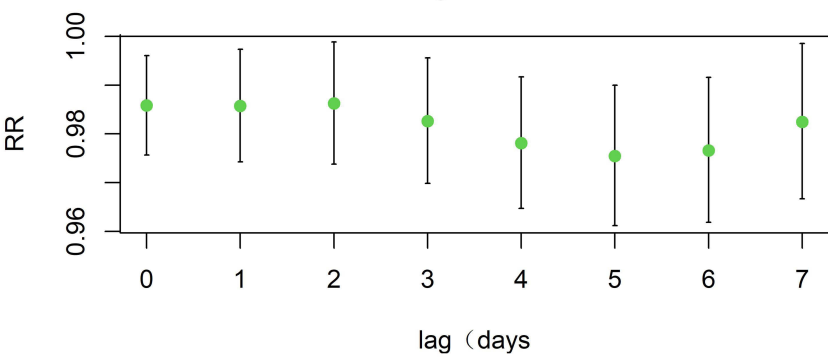

$\mathrm{CO}\left(\mathrm{mg} / \mathrm{m}^{3}\right)$

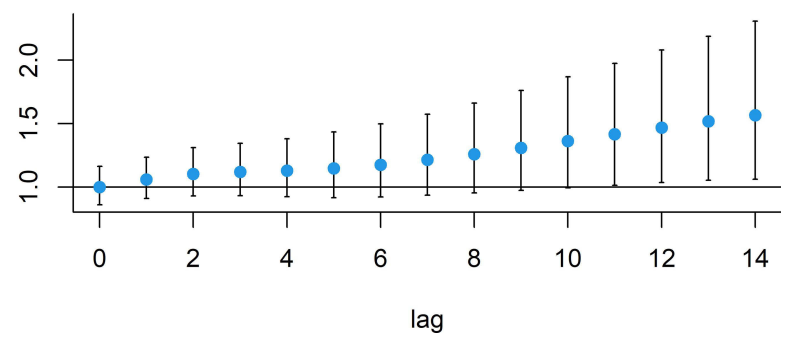

Figure 3 (A) lag-specific relative risks (\%) and (B) cumulative risks (\%) in hospital admissions for gout per 10 (or 1)-unit increase in daily mean concentrations of air pollution in the model.

\section{$\mathrm{O}_{3}$ Effects}

For every $10 \mathrm{ug} / \mathrm{m}^{3}$ increase in $\mathrm{O}_{3}$ concentration, the risk of hospitalizations for gout decreased by $1.4 \%$ ( $R R=0.986,95 \%$ CI: 0.976-0.996, lag 0) (Figure 3). The detailed single-day and cumulative effects of $\mathrm{O}_{3}$ are presented in Table S3. When stratified by season, age, and gender, the effects of $\mathrm{O}_{3}$ exposure were statistically significant in cold seasons $(R R=0.980,95 \%$ CI: $0.967-0.994$, lag0), in people $<65$ years old $(\mathrm{RR}=0.983$, 95\% CI: $0.971-0.995, \operatorname{lag} 0)$, and in males ( $\mathrm{RR}=0.985,95 \%$ CI: $0.975-0.996$, lag0) (Figure 5 and Table S4).

\section{CO Effects}

Figure 3 shows that every $1 \mathrm{mg} / \mathrm{m}^{3}$ increase in $\mathrm{CO}$ concentration was associated with $3.9 \%$ increased risk of hospitalizations for gout ( $\mathrm{RR}=1.039,95 \% \mathrm{CI}: 1.004$ 1.076, lag 11 days). The detailed single-day and cumulative effects of $\mathrm{CO}$ are presented in Table S5. Figure 6 depicts the relationship between $\mathrm{CO}$ exposure and hospitalizations for gout in different subgroups (see Table

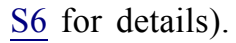

\section{Other Air Pollutions Effects}

In the $\mathrm{PM}_{2.5}$ model, $\mathrm{PM}_{10}\left(r_{s}=0.91\right)$ had a high correlation with $\mathrm{PM}_{2.5}$ (Figure S1). Therefore, $\mathrm{PM}_{10}$ did not enter the final regression model. We found no statistical significance between $\mathrm{PM}_{2.5}$ exposure and hospitalizations for gout. The result was the same in the $\mathrm{PM}_{10}$ and $\mathrm{SO}_{2}$ model (Figure S3). 


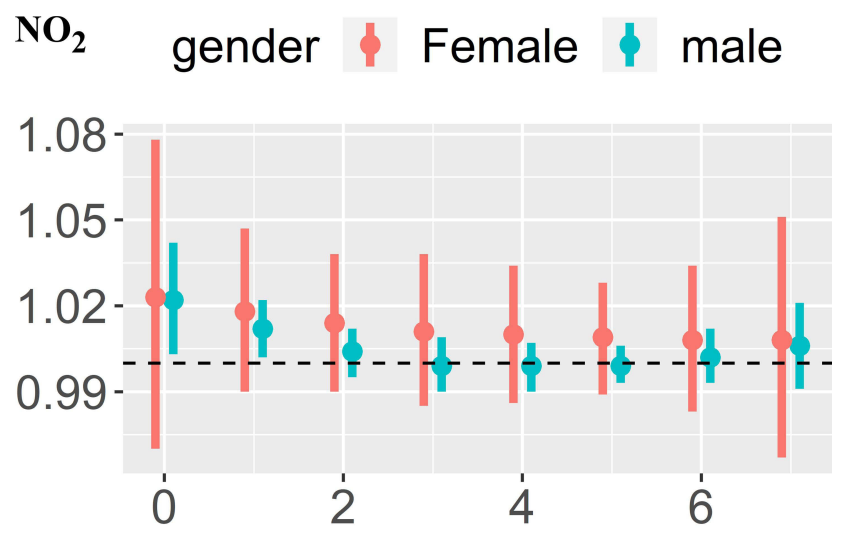

age $\$<65 y+\geq 65 y$

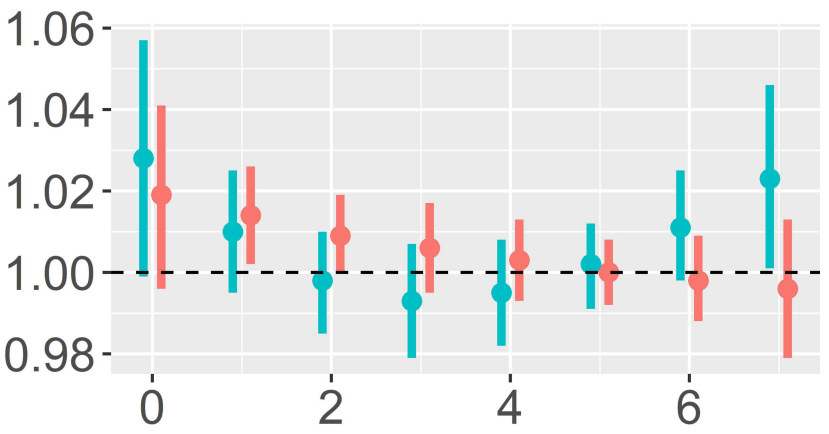

season $\$$ cold $\$$ hot

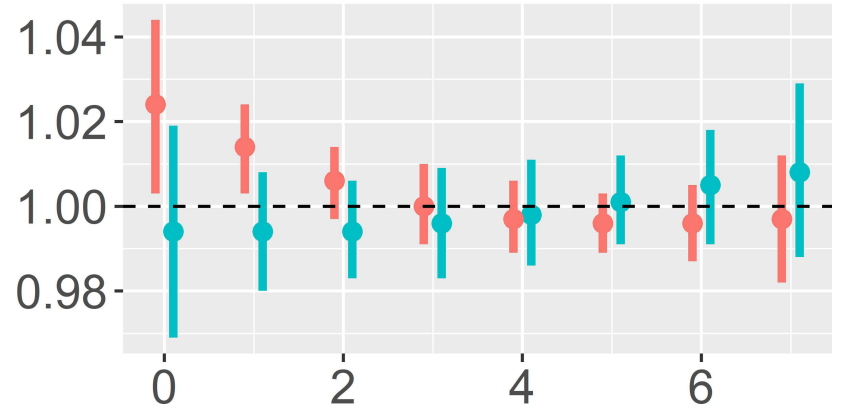

Figure 4 Lag-specific relative risks $(95 \% \mathrm{Cl})$ of gout per 10 unit increase in the daily concentrations of $\mathrm{NO}_{2}$ in models stratified by age, gender, and season.

\section{Sensitivity Analyses}

In the sensitivity analysis, we adjusted the $d f s$ in the $n s$ function for air pollutants, meteorological factors and time in the model. The main results were stable, indicating that the models were robust and reliable (Figures S4-S6).

\section{Discussions}

With the rapid development of the global economy, air pollution has become an environmental problem
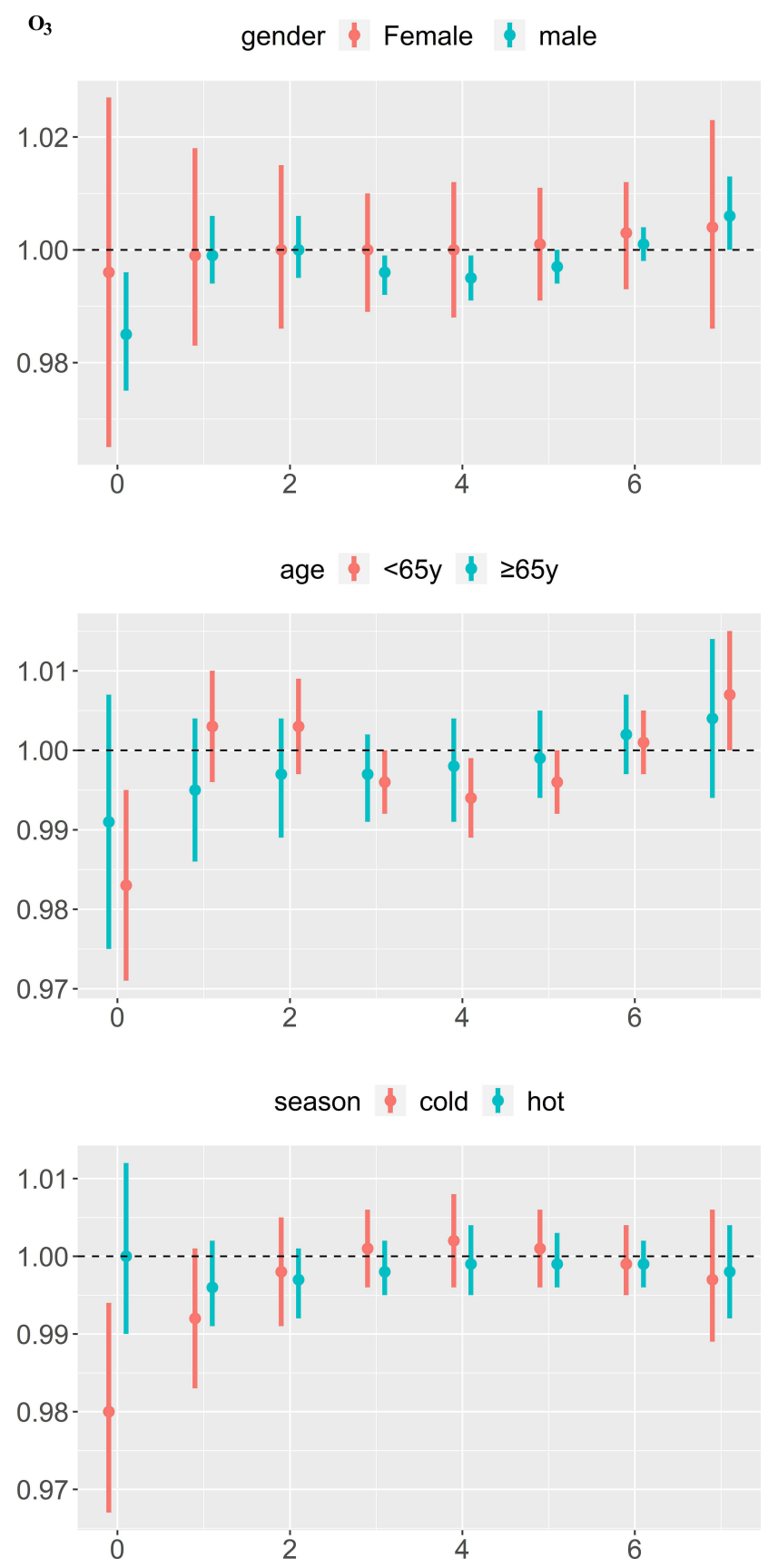

Figure 5 Lag-specific relative risks $(95 \% \mathrm{Cl})$ of gout per 10 unit increase in the daily concentrations of $\mathrm{O}_{3}$ in models stratified by age, gender, and season.

threatening human health. In this study, we found that exposure to $\mathrm{NO}_{2}$ and $\mathrm{CO}$ could significantly the risk of hospitalizations for gout, while exposure to $\mathrm{O}_{3}$ was negatively associated with hospitalizations for gout. Similarly, a study in Taiwan showed that patients exposed to high pollution concentrations of $\mathrm{CO}$ and $\mathrm{PM}_{2.5}$ had a higher incidence of gout than those exposed to low concentrations of pollutants. ${ }^{17}$ Furthermore, in subgroup analysis, we found that 
co
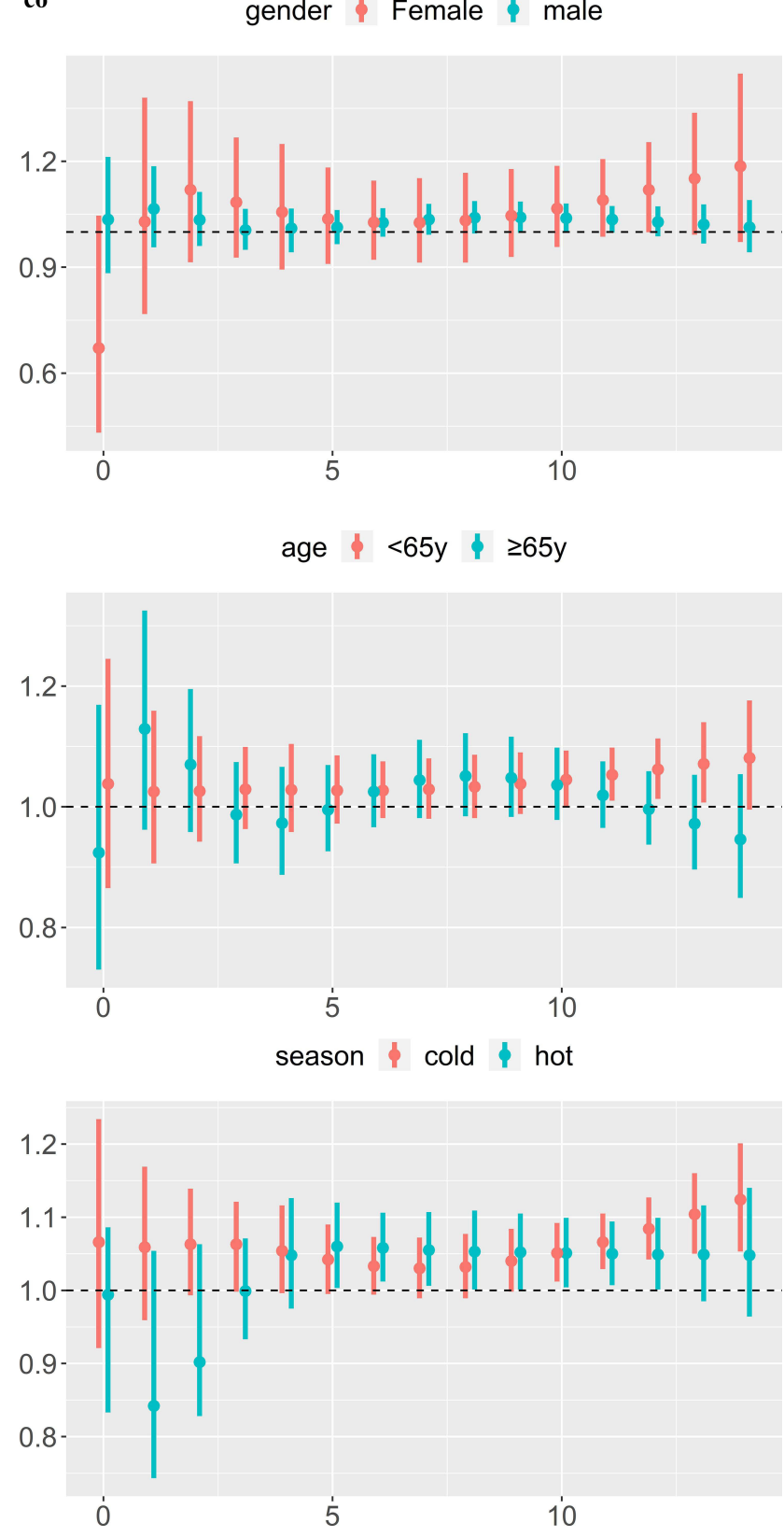

Figure 6 Lag-specific relative risks $(95 \% \mathrm{Cl})$ of gout per I unit increase in the daily concentrations of $\mathrm{CO}$ in models stratified by age, gender, and season.

exposure to $\mathrm{NO}_{2}$ was dramatically considered to be more vulnerable to gout in cold season. Kardeş showed that gout attacks peaked in the autumn, ${ }^{22}$ which is consistent with our findings. It has been reported that MUS can be precipitated in vitro at lower temperatures, ${ }^{23}$ which may explain why exposure to $\mathrm{NO}_{2}$ in cold seasons can increase the risk of hospitalizations for gout. In principle, women consume less alcohol and tobacco than men, which may explain why exposure to high levels of $\mathrm{NO}_{2}$ makes men more vulnerable to gout attacks. Acute gout attacks are caused by interactions between MSU crystals and macrophages, leading to the formation of NLRP3 inflammasomes. NLRP3 activates pre-interleukin (IL)$1 \beta$ caspase-1, which activates IL-1 $\beta$-and drives inflammation. $^{24,25}$ MSU crystals can also induce oxidative stress, which is triggered by the production of reactive oxygen species, thereby stimulating the inflammatory response. ${ }^{26}$ The inflammatory response mechanism caused by $\mathrm{CO}$ and $\mathrm{NO}_{2}$ has many similarities with acute gout attacks. We speculate that inhaled $\mathrm{CO}$ and $\mathrm{NO}_{2}$ may be involved in a stage of the inflammatory pathway and promote the onset of inflammation in patients with gout. Of note, $\mathrm{NO}_{2}$ is proposed to be a vital precursor of a range of secondary pollutants, ${ }^{27}$ which can have a variety of adverse effects on the body, although the role of $\mathrm{NO}_{2}$ in triggering hospitalizations for gout has not been fully understood. With the increase of the number of vehicles in cities, $\mathrm{NO}_{2}$, a common pollutant produced by traffic, will increase. ${ }^{28}$ Hence, we need to carefully monitor this air quality parameter in order to provide evidence for the city's public health policy.

We acknowledge that this study has certain limitations. First, we used the average concentrations of the $\mathrm{NO}_{2}, \mathrm{CO}$, and $\mathrm{O}_{3}$ at 10 fixed monitoring points as the exposure levels, which may not reflect personal exposure. Second, the design of the study was ecological in nature, which may not be immune to ecological fallacy. Individual risk factors for acute gout episodes such as overeating, fasting, excessive alcohol or red meat consumption, and joint damage were not considered. Rainfall was also not adjusted in the model due to data unavailability. Third, we were unable to get those general characteristics of the patients (eg, past medical history, prior medications or other clinical variables). Finally, this is a single city study, due to differences in geography and climate, the results cannot be extended to other regions.

Despite these limitations, there are several advantages. To our knowledge, this was the first time-series study that explores the link between exposure to air pollution and hospitalizations for gout in Anqing City. In addition, we further conducted stratified analyses by gender, age and season to identify the subgroups particularly vulnerable to air pollution effect on hospitalizations for gout. 


\section{Conclusions}

In summary, the present study found that short-term exposure to $\mathrm{NO}_{2}$ and $\mathrm{CO}$ was positively associated with hospitalizations for gout. By contrast, there was a negative relationship between exposure to $\mathrm{O}_{3}$ and hospitalizations for gout. Stratified analysis indicated that exposure to $\mathrm{NO}_{2}$ might be a strong correlation between cold season and hospitalizations for gout.

\section{Data Sharing Statement}

The datasets used and/or analyzed during the current study are available from the corresponding author on reasonable request.

\section{Ethical Considerations}

Since this is an ecological study without any personally identifiable information, thus the informed consent of the research subjects was not needed. All procedures were taken follow the ethical standards of the Declaration of Helsinki; the research protocol was approved by the Ethics Committee of Anhui Medical University.

\section{Ethics Approval and Consent to Participate}

This study was approved by the Ethical Committee of Anhui Medical University (Hefei, Anhui, China).

\section{Acknowledgments}

We appreciate the efforts of all the researchers whose articles were included in this study.

\section{Author Contributions}

All authors made substantial contributions to conception and design, acquisition of data, or analysis and interpretation of data; took part in drafting the article or revising it critically for important intellectual content; agreed to submit to the current journal; gave final approval of the version to be published; and agree to be accountable for all aspects of the work. Yi-Sheng He, Gui-Hong Wang and Qian Wu should be considered as co-first authors.

\section{Funding}

This work did not receive any specific grant from funding agencies in the public, commercial, or not-for-profit sectors.

\section{Disclosure}

The authors confirm that there are no conflicts of interest.

\section{References}

1. Harre U, Derer A, Schorn C, et al. T cells as key players for bone destruction in gouty arthritis? Arthritis Res Ther. 2011;13(6):135. doi:10.1186/ar3508

2. Roddy E, Mallen CD, Doherty M. Gout. BMJ. 2013;347:f5648. doi:10.1136/bmj.f5648

3. Singh JA, Gaffo A. Gout epidemiology and comorbidities. Semin Arthritis Rheum. 2020;50(3s):S11-s16. doi:10.1016/j.semarthrit.20 20.04.008

4. Donaldson K, Stone V, Seaton A, MacNee W. Ambient particle inhalation and the cardiovascular system: potential mechanisms. Environ Health Perspect. 2001;109(Suppl 4):523-527.

5. Törnqvist H, Mills NL, Gonzalez M, et al. Persistent endothelial dysfunction in humans after diesel exhaust inhalation. Am J Respir Crit Care Med. 2007;176(4):395-400. doi:10.1164/rccm.200606-872OC

6. Kabashima K, Otsuka A, Nomura T. Linking air pollution to atopic dermatitis. Nat Immunol. 2016;18(1):5-6. doi:10.1038/ni.3615

7. Song S, Lee K, Lee Y-M, et al. Acute health effects of urban fine and ultrafine particles on children with atopic dermatitis. Environ Res. 2011;111(3):394-399. doi:10.1016/j.envres.2010.10.010

8. Janghorbani M, Momeni F, Mansourian M. Systematic review and metaanalysis of air pollution exposure and risk of diabetes. Eur J Epidemiol. 2014;29(4):231-242. doi:10.1007/s10654-014-9907-2

9. Rao X, Montresor-Lopez J, Puett R, et al. Ambient air pollution: an emerging risk factor for diabetes mellitus. Curr Diab Rep. 2015;15 (6):603. doi:10.1007/s11892-015-0603-8

10. Heydarpour P, Amini H, Khoshkish S, et al. Potential impact of air pollution on multiple sclerosis in Tehran, Iran. Neuroepidemiology. 2014;43(3-4):233-238. doi:10.1159/000368553

11. Roux J, Bard D, Le Pabic E, et al. Air pollution by particulate matter PM(10) may trigger multiple sclerosis relapses. Environ Res. 2017;156:404-410. doi:10.1016/j.envres.2017.03.049

12. Wu Q, Xu Z, Dan Y-L, et al. Association between traffic-related air pollution and hospital readmissions for rheumatoid arthritis in Hefei, China: a time-series study. Environ Pollut. 2021;268(Pt A):115628. doi:10.1016/j.envpol.2020.115628

13. Zhao CN, Mei YJ, Wu GC, et al. Effect of air pollution on hospital admissions for systemic lupus erythematosus in Bengbu, China: a time series study. Lupus. 2019;28(13):1541-1548. doi:10.1177/ 0961203319882503

14. Adami G, Cattani G, Rossini M. Association between exposure to fine particulate matter and osteoporosis: a population-based cohort study. Osteoporos Int. 2021. doi:10.1007/s00198-021-06060-9

15. Adami G, Rossini M, Viapiana O, et al. Environmental air pollution is a predictor of poor response to biological drugs in chronic inflammatory arthritides. ACR Open Rheumatol. 2021;3(7):451-456. doi:10.1002/acr2.11270

16. Ryu HJ, Seo MR, Choi HJ, et al. Particulate matter $(\operatorname{PM}(10))$ as a newly identified environmental risk factor for acute gout flares: a time-series study. Joint Bone Spine. 2021;88(2):105108. doi:10.1016/ j.jbspin.2020.105108

17. $\mathrm{Hu}$ WS, Lin CL. Effect of air pollution on gout development: a nationwide Population-Based observational study. QJM. 2020. doi:10.1093/qjmed/hcaa286

18. You F, Dong S. A preliminary study on ecological economy and sustainable Development strategy of Anqing City. Res Environ Yangtze Basin. 2002.

19. Huang K, Ding K, Yang X-J, et al. Association between short-term exposure to ambient air pollutants and the risk of tuberculosis outpatient visits: a time-series study in Hefei, China. Environ Res. 2020;184:109343. doi:10.1016/j.envres.2020.109343 
20. Bhaskaran K, Gasparrini A, Hajat S, et al. Time series regression studies in environmental epidemiology. Int J Epidemiol. 2013;42 (4):1187-1195. doi:10.1093/ije/dyt092

21. Gasparrini A, Armstrong B, Kenward MG. Distributed lag non-linear models. Stat Med. 2010;29(21):2224-2234. doi:10.1002/sim.3940

22. Kardeş S. Seasonal variation in the internet searches for gout: an ecological study. Clin Rheumatol. 2019;38(3):769-775. doi:10.1007/ s10067-018-4345-2

23. Loeb JN. The influence of temperature on the solubility of monosodium urate. Arthritis Rheum. 1972;15(2):189-192. doi:10.1002/ art. 1780150209

24. Dalbeth N, Merriman TR, Stamp LK. Gout. Lancet. 2016;388 (10055):2039-2052. doi:10.1016/S0140-6736(16)00346-9
25. Punzi L, Scanu A, Ramonda R, et al. Gout as autoinflammatory disease: new mechanisms for more appropriated treatment targets. Autoimmun Rev. 2012;12(1):66-71. doi:10.1016/j.autrev.2012.07.024

26. Zamudio-Cuevas Y, Hernández-Díaz C, Pineda C, et al. Molecular basis of oxidative stress in gouty arthropathy. Clin Rheumatol. 2015;34(10):1667-1672. doi:10.1007/s10067-015-2933-y

27. Chang C-C, Tsai S-S, Ho S-C, et al. Air pollution and hospital admissions for cardiovascular disease in Taipei, Taiwan. Environ Res. 2005;98(1):114-119. doi:10.1016/j.envres.2004.07.005

28. Jerrett M, Finkelstein MM, Brook JR, et al. A cohort study of traffic-related air pollution and mortality in Toronto, Ontario, Canada. Environ Health Perspect. 2009;117(5):772-777. doi:10.128 9/ehp.11533
Journal of Inflammation Research

\section{Publish your work in this journal}

The Journal of Inflammation Research is an international, peerreviewed open-access journal that welcomes laboratory and clinical findings on the molecular basis, cell biology and pharmacology of inflammation including original research, reviews, symposium reports, hypothesis formation and commentaries on: acute/chronic inflammation; mediators of inflammation; cellular processes; molecular

\section{Dovepress}

mechanisms; pharmacology and novel anti-inflammatory drugs; clinical conditions involving inflammation. The manuscript management system is completely online and includes a very quick and fair peerreview system. Visit http://www.dovepress.com/testimonials.php to read real quotes from published authors. 